\title{
Evaluating Web-Based Platforms and Traditional Methods for Recruiting Tattoo Artists: Descriptive Survey Research Study
}

Jessica L C Sapp ${ }^{1^{*}}$, DrPH, MPH; Robert L Vogel ${ }^{2^{*}}$, PhD; Joseph Telfair ${ }^{2^{*}}$, DrPH, MPH, MSW; Julie K Reagan ${ }^{3^{*}}$, $\mathrm{PhD}, \mathrm{JD}, \mathrm{MPH}$

\footnotetext{
${ }^{1}$ Public Health Program, School of Health Sciences, American Public University System, Charles Town, WV, United States

${ }^{2}$ Dean's Office, Jiann-Ping Hsu College of Public Health, Georgia Southern University, Statesboro, GA, United States

${ }^{3}$ School of Health Administration, College of Health Professions, Texas State University, San Marcos, TX, United States

*all authors contributed equally
}

\section{Corresponding Author:}

Jessica L C Sapp, DrPH, MPH

Public Health Program

School of Health Sciences

American Public University System

$111 \mathrm{~W}$ Congress St

Charles Town, WV, 25414

United States

Phone: 13214061161

Email: jessica.sapp2@mycampus.apus.edu

\begin{abstract}
Background: Almost one-third of US adults (29\%) have a tattoo, and almost half (47\%) of millennials reported having a tattoo. With more people getting tattoos, there is an increased risk of infectious diseases, skin infections, and allergic reactions. Tattoo artists can influence these health risks with their standards of practice, tattoo inks, and sterilization techniques. Although tattoos are becoming mainstream, it was unclear if tattoo artists would be a hard-to-reach population. Using social media sites represents a promising method for recruiting tattoo artists for Web-based survey studies.

Objective: The aim of this study was to evaluate various Web-based platforms and traditional methods for recruiting tattoo artists into a descriptive Web-based survey study.

Methods: Recruitment occurred via Facebook ads, Instagram, Twitter, website, Web-based advertisement, emails, and postcards mailed to tattoo shops.

Results: Recruitment methods resulted in 2332 respondents, of which 1845 answered question 1, "Are you a tattoo artist?" Only 1571 were tattoo artists. Facebook ads recruited the most study participants. Facebook accounted for 1228 (1228/1571, $78.17 \%$ ) respondents who were tattoo artists. This number surpassed the next leading category of HTTP Referer unknown, which had $268(268 / 1571,17.06 \%)$. The Tattoo Survey 2015 website recruited $45(45 / 1571,2.86 \%)$ tattoo artists, whereas other Web-based sources contributed to the recruitment of $28(28 / 1571,1.78 \%)$ tattoo artists. Twitter and email had the lowest response rate with only $0.06 \%(1 / 1571)$ each.

Conclusions: Social media sites enhanced survey participation, making it easier to reach tattoo artists nationwide. Of the recruitment methods used, Facebook ads were the most effective option, both for cost and recruitment rates. This study's findings extend those of the previous research studies that demonstrated the timeliness, ease, and effectiveness of using Facebook ads for recruitment.
\end{abstract}

(JMIR Dermatol 2019;2(1):e14151) doi: $10.2196 / 14151$

\section{KEYWORDS}

tattooing; ink; social media; internet; survey and questionnaires; United States; adult; skin diseases; advertising as topic 


\section{Introduction}

Recruiting for a national study has changed in today's research climate with the continued reduction of home landline telephones. Accessing participants through the internet and social media has become a common substitute and an asset in national surveys. There are many social media platforms including Facebook, Instagram, Twitter, Pinterest, Snapchat, LinkedIn, and YouTube, all of which are potential sources for recruitment. Even with their potential for recruitment, it is important to understand the research limitations of social media based on the platforms' infrastructures, such as self-selection bias.

Facebook continues to be the primary social media platform used in the United States [1]. According to a recent survey, 68\% of US adults use Facebook. The percentage increases in younger age groups with $88 \%$ of 18 - to 29 -year-olds using some type of social media and $78 \%$ in people aged 30 to 49 years [1]. As of September 2018, Facebook reported 1.49 billion daily active users and 2.27 billion monthly active users [2].

Following Facebook, Instagram is the next most used platform among US adults (35\%) [1]. Instagram is used to share images and is widely used by tattoo artists. As of December 21, 2018, there have been over 19 million public posts using the hashtags \#tattooist (4.4 million), \#tattooer (3.4 million), or \#tattooartist (11.4 million). There have been over 150 million public posts using \#tattoo (103.4 million) or \#tattoos (46.9 million) [3-7].

According to the New York survey service Harris Poll, almost one-third of US adults (29\%) have a tattoo, and almost half (47\%) of millennials reported having a tattoo [8]. With more people getting tattoos, there is an increased risk of skin infections, such as Methicillin-resistant Staphylococcus aureus, nontuberculous mycobacterial infections- Mycobacterium chelonae and Mycobacterium abscessus, and pseudoepitheliomatous hyperplasia [9-13]. Skin infections from tattoos can be a consequence of unsterile equipment, contaminated tattoo ink, or using tap water to dilute tattoo ink ([14]; Griffin et al, in press). "A person can have an allergic reaction to various components in the ink which can result in an itchy rash at the tattoo site or other skin condition including granulomas - small knots or bumps, or keloids - raised areas caused by overgrowth of scar tissue" [15].

In the original study, the recruitment goal was at least 461 tattoo artists who primarily tattooed in the United States, although 1315 participants were included in the study after all inclusion and exclusion criteria [15]. The purpose of this paper was to evaluate various Web-based platforms and traditional methods for recruiting tattoo artists into a descriptive Web-based survey study.

\section{Methods}

\section{Study Overview}

The study aimed to gain an understanding and describe the perceptions and opinions of tattoo artists regarding tattoo regulations in the United States. The study used a descriptive survey research design, and data were collected through a Web-based survey. Tattoo artists were recruited from September 2015 to February 2016. Tattoo artists were eligible to participate if they were aged 18 years and older and primarily tattooed in the United States [15].

\section{Recruitment}

Recruitment for the research study was conducted through various processes and platforms. Traditional advertising, Web-based marketing, Web-based advertisements, social media, snowball sampling, tattoo conventions, and tattoo registries were used.

Marketing strategies are prominent for selling products or services, and branding is an intricate part of marketing. According to North Star Marketing, brand consistency helps manage perceptions and eliminates brand confusion [16]. For consistency and branding, all recruiting materials, websites, and social media domains used Tattoo Survey 2015 for easy recognition; this included the website, Tattoo Survey 2015; Facebook page, Tattoo Survey 2015; Twitter, Tattoo Survey 2015; and Instagram, Tattoo Survey 2015. Furthermore, a consistent image accompanied the websites and social media pages to maximize branding recognition. When appropriate, consistent hashtags (\#) were used to accompany various Web-based posts and images. These included \#TattooSurvey2015, \#rockthesurvey, and \#futureDrJessica.

\section{Tattoo Convention and Emails}

A tattoo convention was attended in September 2015 in Tampa, Florida, for networking to recruit potential participants. Business cards were collected from the tattoo artists' booths and 131 emails were sent in October 2015 with an anonymous survey link and details regarding the research project. Tattoo artists were represented from 109 tattoo shops in 24 states. It was discovered at the tattoo convention that most tattoo artists used Instagram to advertise their tattoos and artwork. This detection was the determinant to include Instagram and Twitter in recruiting (in addition to Facebook) them.

\section{Facebook}

Facebook ads were the predominantly used Web-based advertisements. In total, there were 6 Facebook ad campaigns used for various purposes. A campaign was used to promote the Facebook page to increase Likes of the page (Figure 1). The target audience was individuals that had an interest in tattoos, located in the United States, and aged 18 years and older. This campaign had the fewest selection criteria. The second campaign was to promote the Tattoo Survey 2015 website that directed individuals who clicked on the advertisement to the website (Figure 1). The remaining 4 campaigns were used to send individuals directly to the Web-based survey. 
Figure 1. Facebook ads-Tattoo Survey 2015 Facebook page and website.
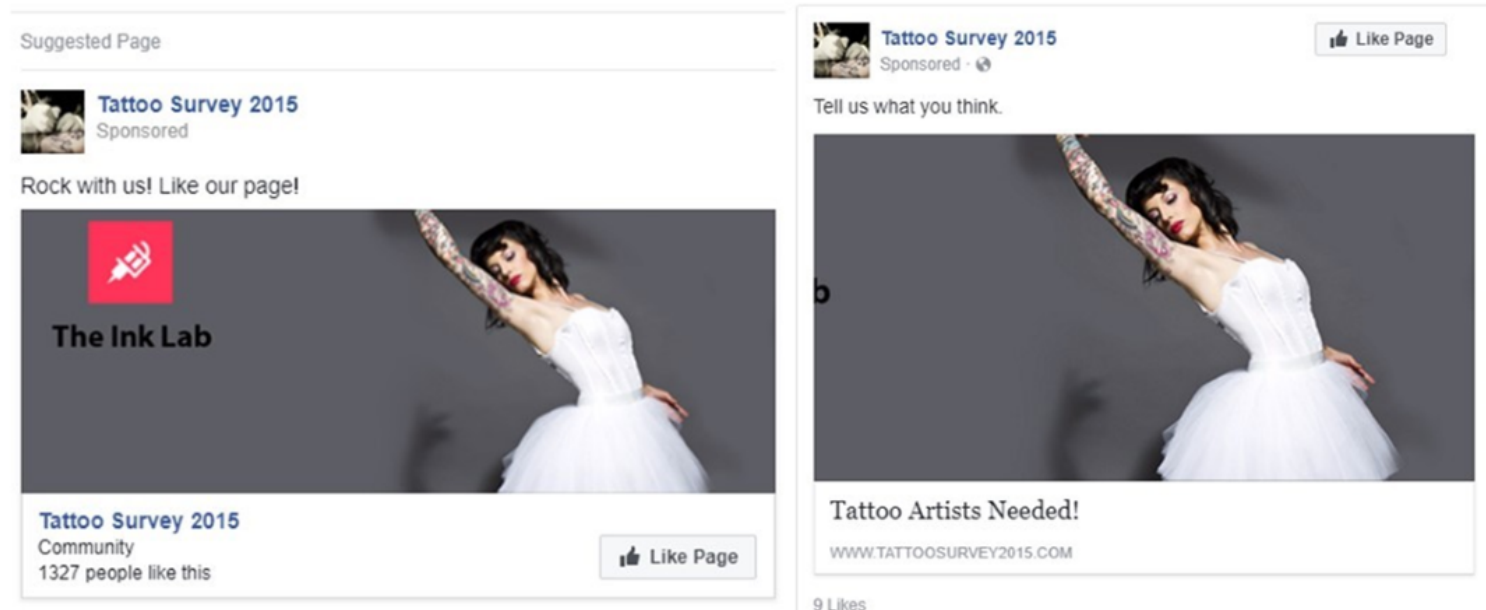

Tattoo Artists Needed!

WWWTATTOOSURVEY2015.COM

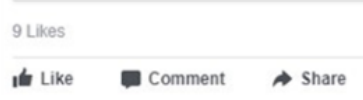

The target audience for campaign 3 (Figure 2) were individuals aged 18 years and older, located in the United States, with special interests, such as tattoo machines, tattoo ink, tattoo artist magazine, and tattooist. Campaigns 4, 5, and 6 (Figure 3) had

Florida region. The campaigns used various images, headers, and hashtags. The Facebook ads were staggered at different time intervals between September 29, 2015, and January 6, 2016. the same target audiences, except they were specific to the

Figure 2. Facebook ad-take survey.

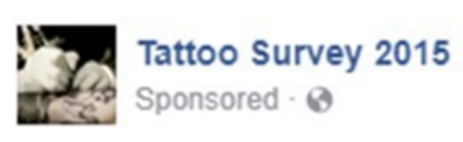

Like Page

Tell us what you think.

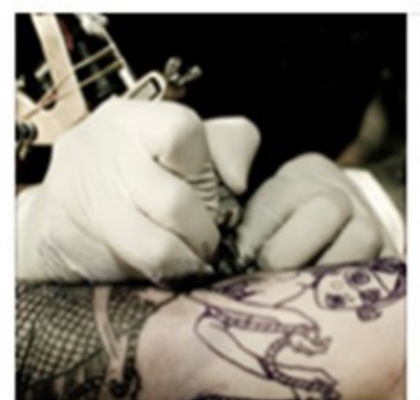

Are you a Tattoo Artist?

GEORGIASOUTHERN.CO1.QUALTRICS.COM

392 Likes 186 Comments 84 Shares

I Like Comment $\rightarrow$ Share


Figure 3. Facebook ads-Florida.

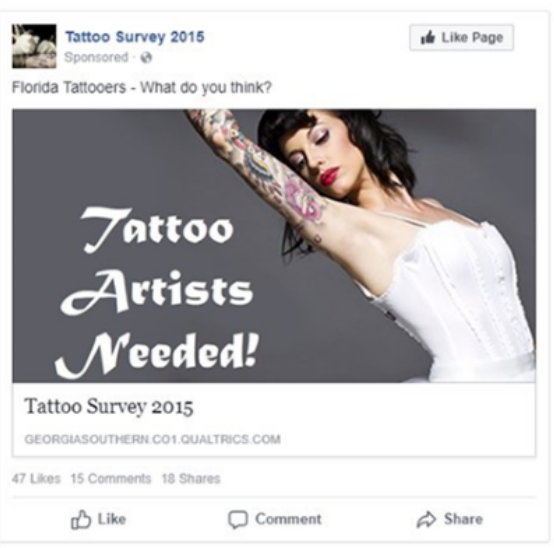

\section{Instagram}

Tattoo Survey 2015 Instagram (Figure 4) was created to network and recruit tattoo artists by following tattoo artists and receiving followers on Instagram. Tattoo Survey 2015 followed over 1300 tattoo artists and had about 100 followers during the study. Various images $(n=25)$ were posted for recruitment from September 30, 2015, to January 23, 2016. The anonymous survey link was available in the biography section of the Instagram profile (the link was changed to the study results link once it concluded).
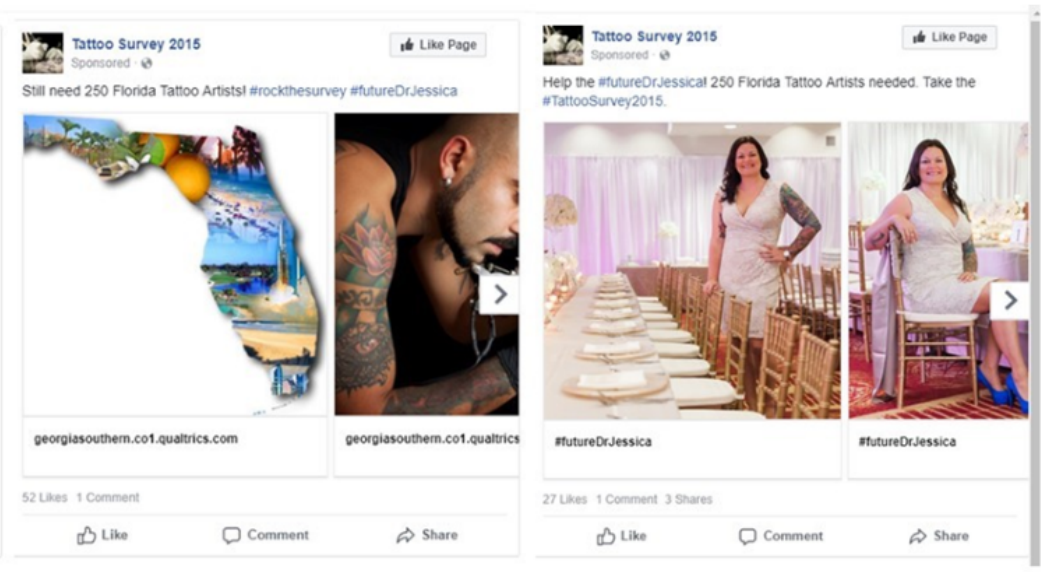

Figure 4. Tattoo Survey 2015 Instagram account.

\section{Twitter}

Tattoo Survey 2015 Twitter (Figure 5) was created to network and recruit tattoo artists by tweeting information, following tattoo artists, and receiving followers on Twitter. Tattoo Survey 2015 followed about 90 tattoo artists and had about 17 followers during the study. Various tweets $(n=32)$ were posted for recruitment from September 30, 2015, to February 2, 2016. The anonymous survey link was provided in a pinned tweet for easy access but also included multiple tweets (pinned tweet was changed to the study results link once it concluded).

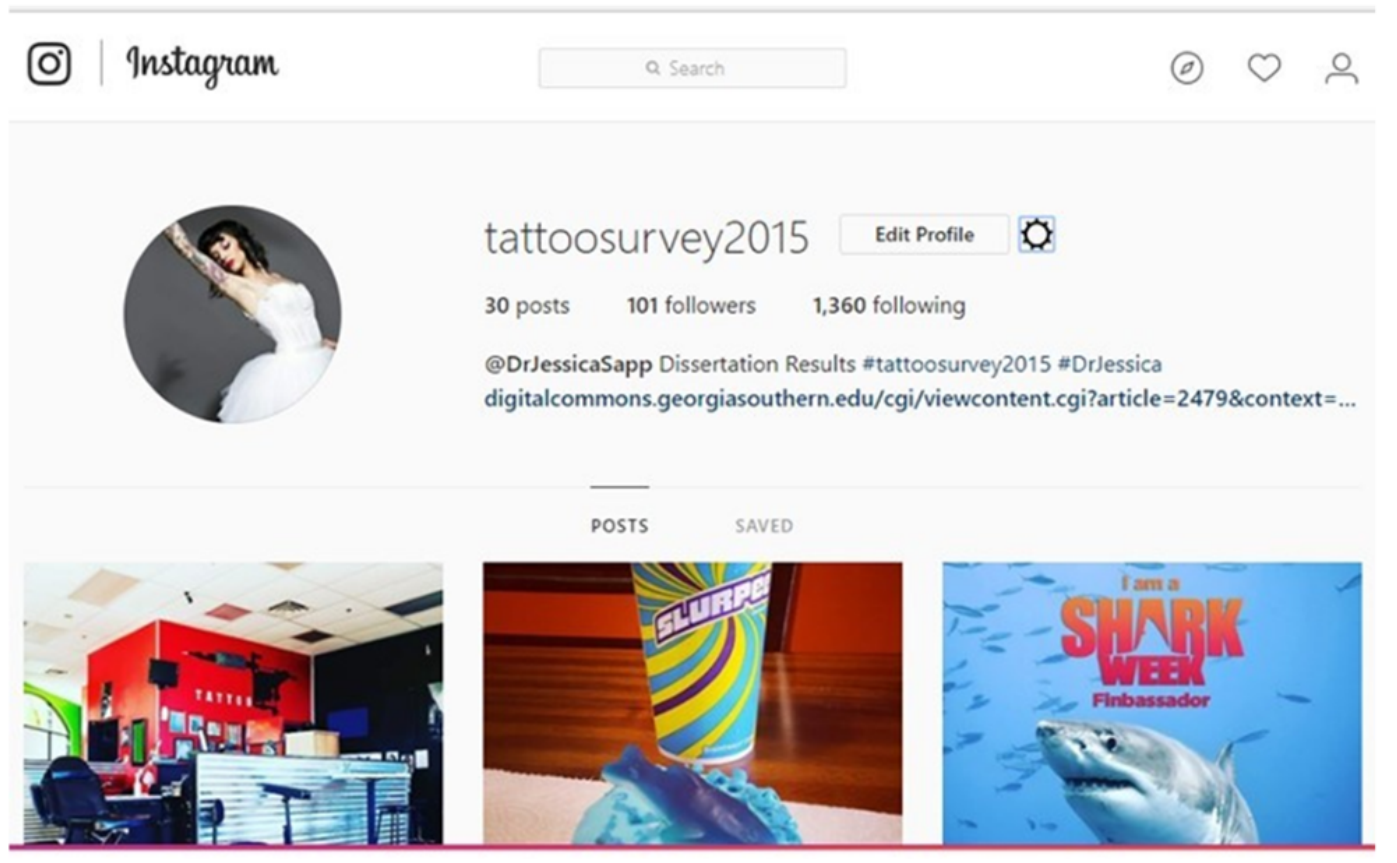


Figure 5. Tattoo Survey 2015 Twitter account.

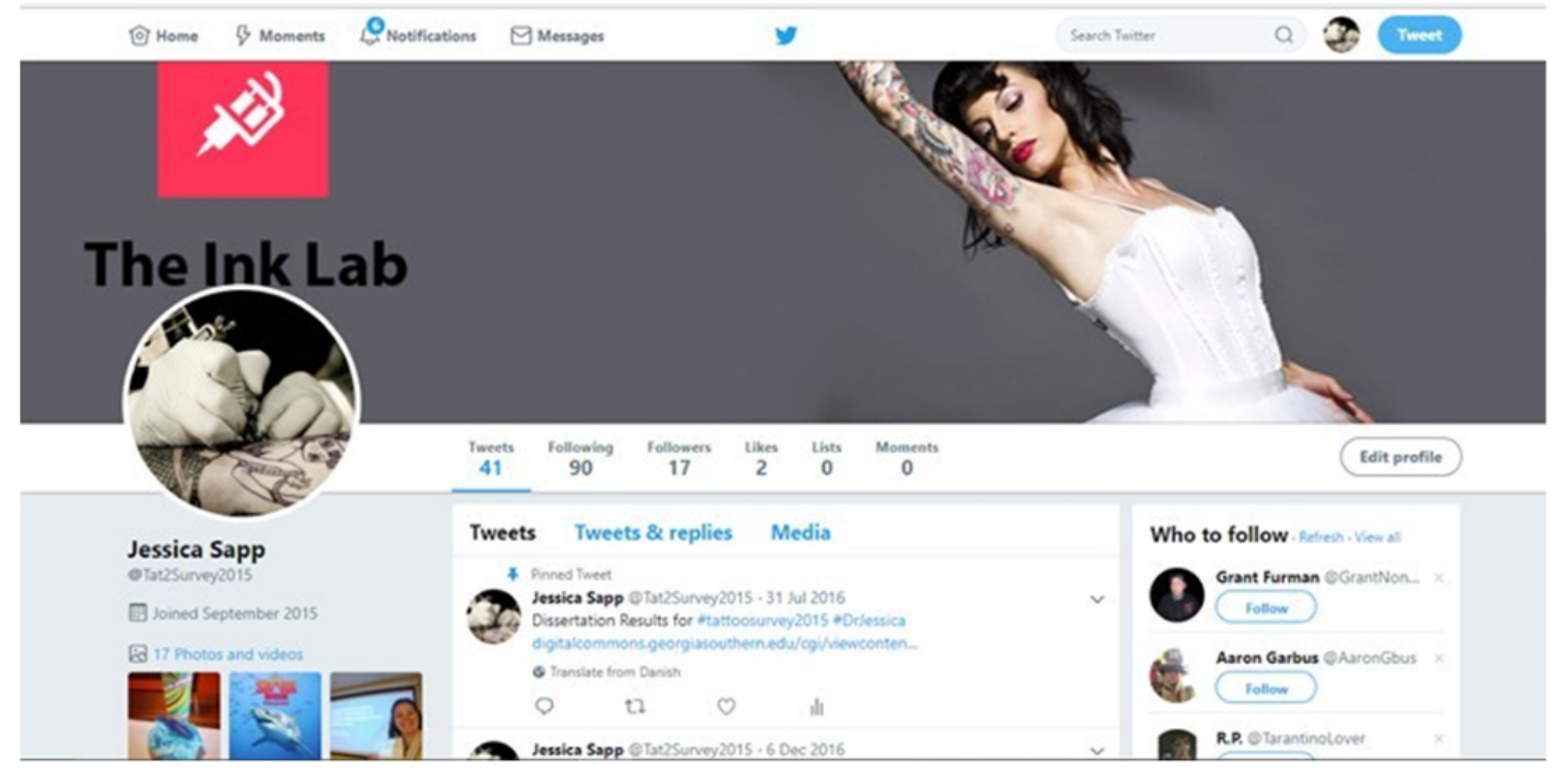

\section{Website}

A website (Figure 6) was used to provide a central location to direct participants to complete the survey and provide valuable information including consent and research disclosures. The website furnished more details than the social media platforms. All social media pages (Facebook, Instagram, and Twitter) included links to the survey and website.

\section{Website Advertisement}

World Tattoo Events is a website that is considered the Web-based calendar for international tattoo conventions [17]. Tattoo conventions attract many tattoo artists. It would be expected that the primary audience for World Tattoo Events is the tattoo artists. As a result, a Web-based banner was displayed on the website (Figure 7).

Figure 6. Tattoo Survey 2015 website.

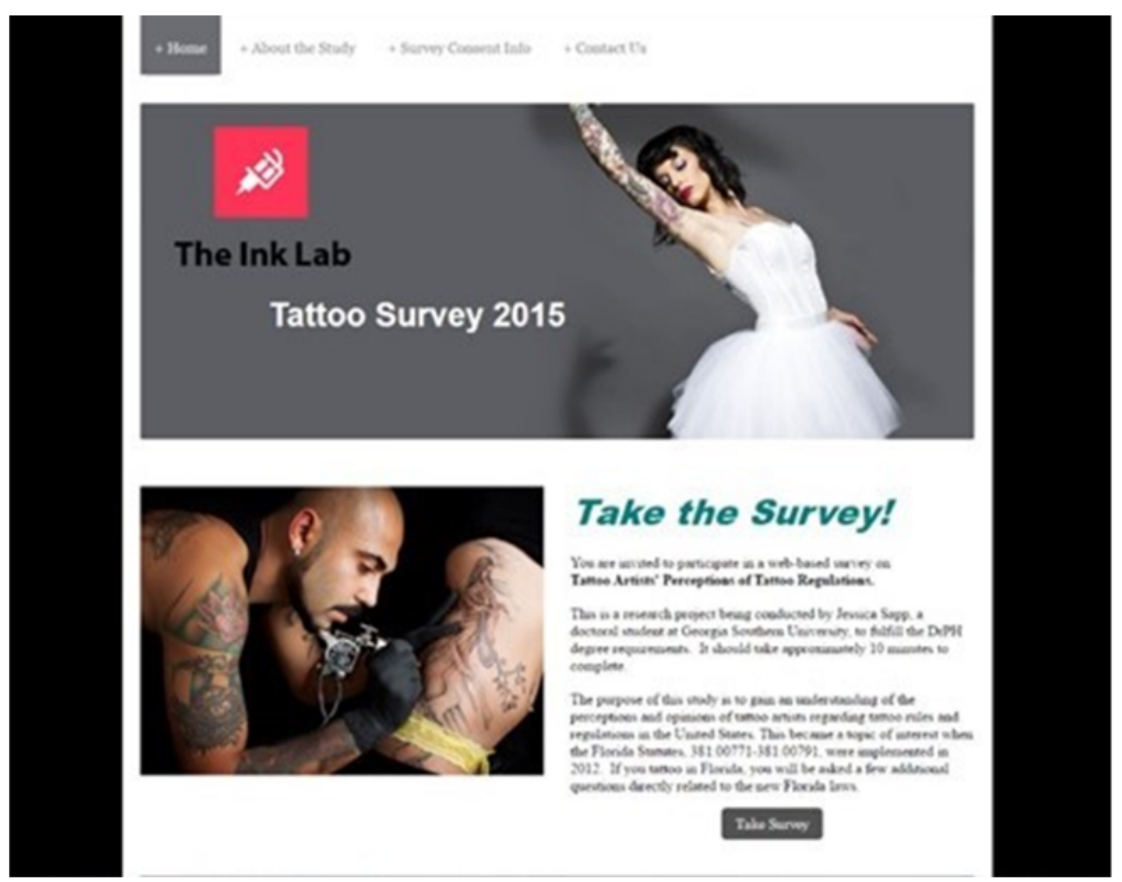


Figure 7. Website advertisement on World Tattoo Events homepage.

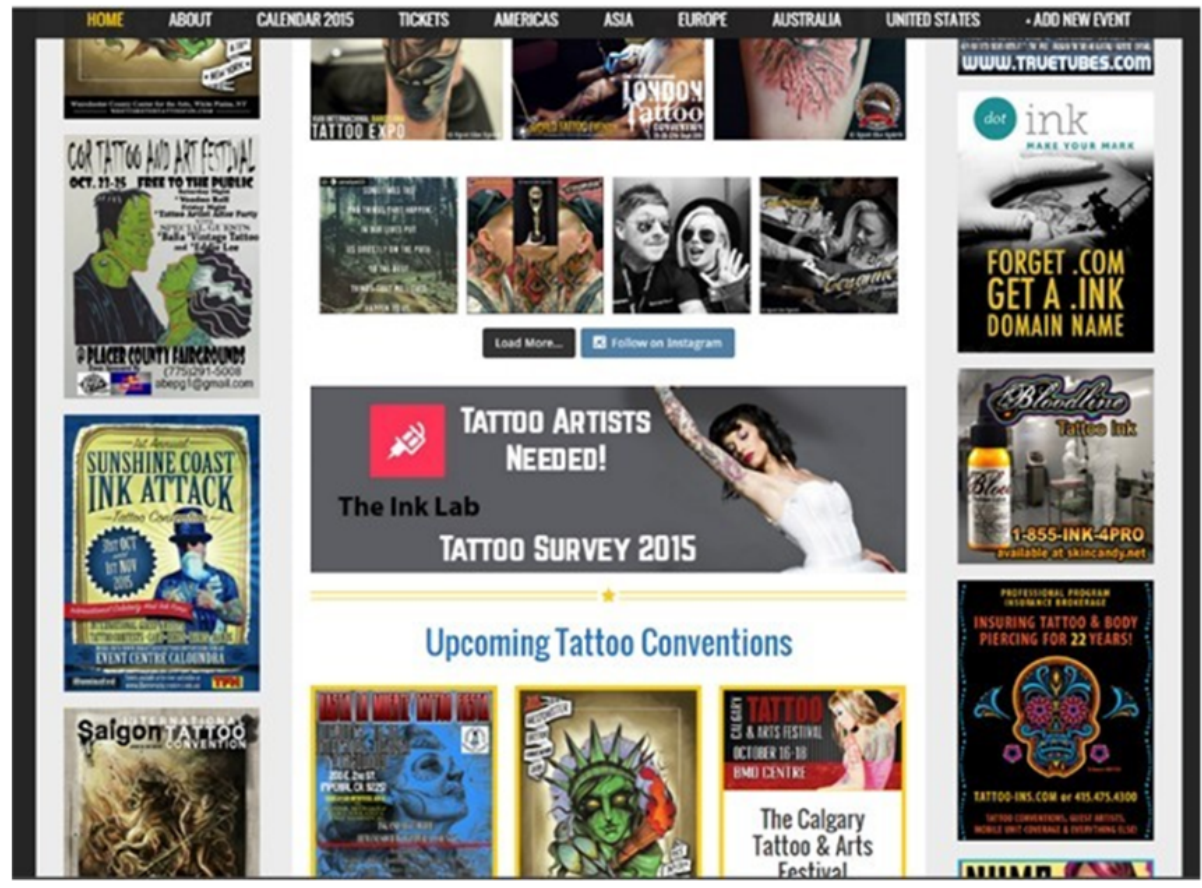

Figure 8. Tattoo Survey 2015 postcard (front and back).

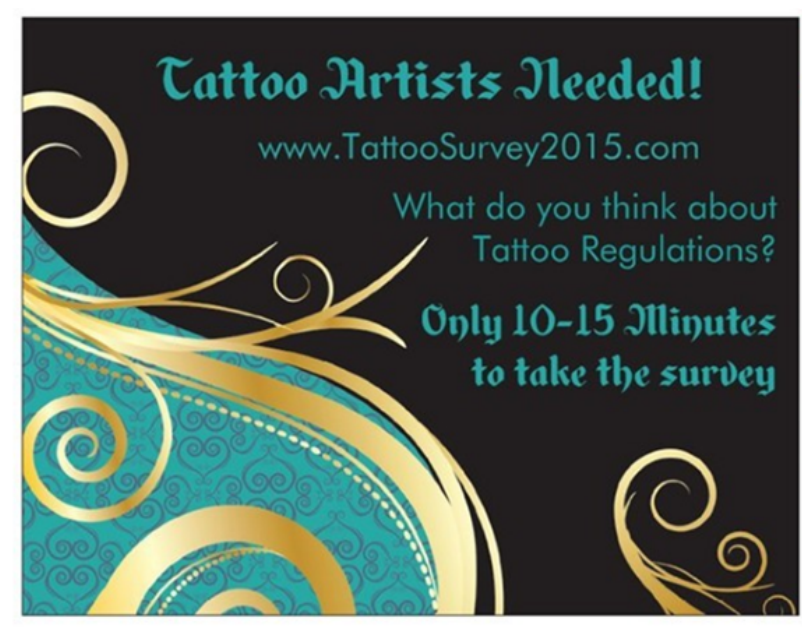

\section{Postcards}

The Florida Department of Health has a Web-based registry of tattoo shop inspections [18]. This registry was used to obtain addresses of tattoo establishments throughout Florida. Over 400 postcards (Figure 8) were distributed to local tattoo establishments via mail, and digital versions were posted on the Web. Because there were only about 10 respondents who were tattoo artists in the 4 weeks following the mailout, no additional postcards were mailed for recruitment.

\section{Snowball Sampling}

Snowball sampling has evolved with technology developments and social networking sites $[19,20]$. People continue to increase Web-based interactions and use social media platforms for daily conversation [21]. Snowball sampling included not only word-of-mouth, but also viral interactions, such as Facebook postings, repostings, and sharing through friend networks.

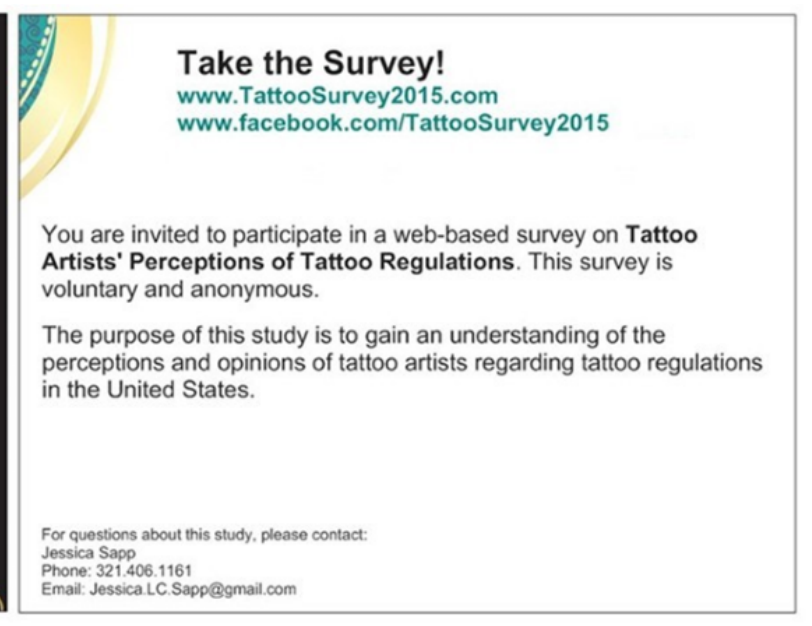

\section{Measures}

Qualtrics software was used for the survey tool. Qualtrics provided built-in embedded data including HTTP Referer [22]. The HTTP Referer data were used to determine the Web page the respondent was on when he or she clicked the survey link. This information was collected to determine the frequency of recruitment sources and descriptive characteristics among participants based on the referrer source. Demographics were self-reported by study participants in the Web-based survey.

Facebook ads manager includes standard metrics that were used to assess Facebook ads performance. Similar to the previous studies using Facebook ads [23-27], reach, unique clicks, costs, cost per click, and daily budget were examined. Duration (number of days) of Facebook ads was also reviewed. Facebook measures reach as the number of people who saw the ad at least once. Impressions are the number of times the ad was on screen, which can include multiple views by the same person. Unique clicks are the number of people who clicked on the ad. 


\section{Results}

Recruitment methods resulted in 2332 respondents, of which 1845 answered question 1, “Are you a tattoo artist?” Only 1571 were tattoo artists (ie, answered yes). In the original study, there were 1315 study participants after all exclusions [15].

\section{Recruitment}

With the various recruitment methods, Facebook recruited the most study participants (Table 1). For the recruitment sample, Facebook accounted for $1228(1228 / 1571,78.17 \%)$ respondents who were tattoo artists. This number dominated all recruitment efforts and surpassed the next leading category of referrer unknown, which had $268(268 / 1571,17.06 \%)$. The Tattoo Survey 2015 website recruited $45(45 / 1571,2.86 \%)$ tattoo artists, whereas other Web-based sources recruited 28 (28/1571, $1.78 \%)$. Twitter and email had the lowest response rate with only $0.06 \%(1 / 1571)$ each.

\section{Facebook Ads}

Facebook ads were the major contributor to recruiting tattoo artists in the Web-based survey. The Take Survey ad (campaign 3 ) had the best response with 3234 unique clicks and a reach of 92,799 . This resulted in a US $\$ 0.09$ cost per click. There were 6 campaigns with a combined 7129 unique clicks and a reach of 282,664. All Facebook ads cost US \$1353.01. Table 2 displays the performance of each Facebook ad.

\section{Participant Characteristics}

Of the 1571 tattoo artists (Table 3), the majority were recruited through Facebook (1228/1571, 78.17\%). Most of the participants were male $(808 / 1571,51.43 \%)$ and had been tattooing for 1 to 10 years $(793 / 1571,50.48 \%)$. Almost half of the participants were aged 25 to 44 years $(674 / 1571,42.90 \%)$. The majority of respondents were full-time tattoo artists $(867 / 1571,55.19 \%)$ and tattooed in a tattoo shop $(1013 / 1571,64.48 \%)$ but did not own a tattoo shop $(952 / 1571,60.59 \%)$.

Table 1. Recruitment referrer source for participants who answered yes to question 1 (Are you a tattoo artist?) (N=1571).

\begin{tabular}{ll}
\hline Referrer source & Frequency, n $(\%)$ \\
\hline Facebook & $1228(78.17)$ \\
Twitter & $1(0.06)$ \\
Website & $45(2.86)$ \\
Email & $1(0.06)$ \\
Other Web-based source & $28(1.78)$ \\
Referrer unknown & $268(17.06)$ \\
Total & $1571(100.00)$ \\
\hline
\end{tabular}

Table 2. Facebook ads.

\begin{tabular}{|c|c|c|c|c|c|c|}
\hline Facebook ads & Clicks & Reach & Cost, US \$ & Cost per click, US \$ & Daily budget, US \$ & Duration, days \\
\hline Tattoo survey ${ }^{\mathrm{a}}$ & 3527 & 92,799 & 319.88 & 0.09 & 5 & 63 \\
\hline $\begin{array}{l}\text { Tattoo survey } 2015 \\
\text { Facebook page }\end{array}$ & 452 (page likes) & 6318 & 49.99 & 0.11 & 5 & 10 \\
\hline $\begin{array}{l}\text { Tattoo Survey } 2015 \\
\text { website }\end{array}$ & 148 & 18,470 & 49.99 & 0.34 & 5 & 10 \\
\hline Florida tattooers ${ }^{\mathrm{a}}$ & 514 & 43,979 & 219.75 & 0.43 & 10 & 22 \\
\hline 300 Florida $^{\mathrm{a}}$ & 1924 & 75,524 & 375.74 & 0.20 & 10 & 35 \\
\hline FL250 ${ }^{a}$ & 708 & 39,047 & 287.70 & 0.41 & $350^{\mathrm{b}}$ & 25 \\
\hline
\end{tabular}

${ }^{\mathrm{a}}$ Facebook ads directly linked to the Web-based survey.

bifetime budget of US $\$ 350$ was used instead of a daily budget. 
Table 3. Descriptive characteristics of study sample based on the referrer source $(\mathrm{N}=1571)$.

\begin{tabular}{|c|c|c|c|c|c|c|}
\hline Variables & $\begin{array}{l}\text { Facebook }(\mathrm{n}=1228), \\
\mathrm{n}(\%)\end{array}$ & $\begin{array}{l}\text { Twitter }(\mathrm{n}=1) \\
\mathrm{n}(\%)\end{array}$ & $\begin{array}{l}\text { Website }(\mathrm{n}=45) \\
\mathrm{n}(\%)\end{array}$ & $\begin{array}{l}\text { Email }(\mathrm{n}=1) \\
\mathrm{n}(\%)\end{array}$ & $\begin{array}{l}\text { Other Web-based source } \\
(\mathrm{n}=28), \mathrm{n}(\%)\end{array}$ & $\begin{array}{l}\text { Referrer unknown } \\
(\mathrm{n}=268), \mathrm{n}(\%)\end{array}$ \\
\hline \multicolumn{7}{|l|}{ Gender } \\
\hline Male & $639(52.04)$ & $0(0)$ & $20(44)$ & $0(0)$ & $14(50)$ & $135(50.4)$ \\
\hline Female & $29(2.36)$ & $0(0)$ & $4(9)$ & $0(0)$ & $2(7)$ & $9(3.4)$ \\
\hline Missing & $560(45.60)$ & $1(100)$ & $21(47)$ & $1(100)$ & $12(43)$ & $124(46.3)$ \\
\hline \multicolumn{7}{|l|}{ Age (years) } \\
\hline $18-24$ & $74(6.03)$ & $0(0)$ & $4(9)$ & $0(0)$ & $4(14)$ & $9(3.4)$ \\
\hline $25-34$ & $273(22.23)$ & $0(0)$ & $4(9)$ & $0(0)$ & $6(21)$ & $52(19.4)$ \\
\hline $35-44$ & $258(21.01)$ & $0(0)$ & $9(20)$ & $0(0)$ & $4(14)$ & $68(25.4)$ \\
\hline $45-54$ & $60(4.86)$ & $0(0)$ & $5(11)$ & $0(0)$ & $1(4)$ & $12(4.5)$ \\
\hline $55-64$ & $2(0.16)$ & $0(0)$ & $1(2)$ & $0(0)$ & $0(0)$ & $1(0.4)$ \\
\hline $65-74$ & $0(0)$ & $0(0)$ & $0(0)$ & $0(0)$ & $1(4)$ & $0(0)$ \\
\hline$>75$ & $0(0)$ & $0(0)$ & $1(2)$ & $0(0)$ & $0(0)$ & $0(0)$ \\
\hline Missing & $561(45.68)$ & $1(100)$ & $21(47)$ & $1(100)$ & $12(43)$ & $126(47.0)$ \\
\hline \multicolumn{7}{|l|}{ How long tattooing (years) } \\
\hline$<1$ & $52(4.23)$ & $0(0)$ & $3(7)$ & $0(0)$ & 4 (14) & $9(3.4)$ \\
\hline $1-5$ & $358(29.15)$ & $1(100)$ & $10(22)$ & $0(0)$ & $9(32)$ & $53(19.8)$ \\
\hline $6-10$ & $277(22.56)$ & $0(0)$ & $7(16)$ & $1(100)$ & $6(21)$ & $71(26.5)$ \\
\hline $11-15$ & $159(12.95)$ & $0(0)$ & $4(9)$ & $0(0)$ & $2(7)$ & $37(3.0)$ \\
\hline $16-20$ & $77(6.27)$ & $0(0)$ & $5(11)$ & $0(0)$ & $1(4)$ & $21(7.8)$ \\
\hline$>20$ & $88(7.17)$ & $0(0)$ & $7(16)$ & $0(0)$ & $3(11)$ & $17(6.3)$ \\
\hline Missing & $217(17.67)$ & $0(0)$ & $9(20)$ & $0(0)$ & $3(11)$ & $60(22.4)$ \\
\hline \multicolumn{7}{|c|}{ Employment status of tattooer } \\
\hline Full-time tattoo artist & $689(56.11)$ & $0(0)$ & $26(58)$ & $1(100)$ & $11(39)$ & $140(52.2)$ \\
\hline Part-time tattoo artist & $109(8.88)$ & $0(0)$ & $5(11)$ & $0(0)$ & $3(11)$ & $24(9.0)$ \\
\hline Intermittent tattoo artist & $112(9.12)$ & $0(0)$ & $3(7)$ & $0(0)$ & $4(14)$ & $23(8.6)$ \\
\hline Tattoo as a hobby & $132(10.75)$ & $1(100)$ & $1(2)$ & $0(0)$ & $5(18)$ & $24(9.0)$ \\
\hline Missing & $186(15.15)$ & $0(0)$ & $10(22)$ & $0(0)$ & $5(18)$ & $57(21.3)$ \\
\hline \multicolumn{7}{|l|}{ Location of tattooing } \\
\hline Tattoo shop & $812(66.12)$ & $0(0)$ & $29(64)$ & $1(100)$ & $14(50)$ & $157(58.6)$ \\
\hline Tattoo convention & $286(23.29)$ & $0(0)$ & $12(27)$ & $1(100)$ & $4(14)$ & $60(22.4)$ \\
\hline Home & $308(25.08)$ & $0(0)$ & $8(18)$ & $0(0)$ & $12(43)$ & $74(27.6)$ \\
\hline Other & $75(6.11)$ & $1(100)$ & $3(7)$ & $0(0)$ & $1(4)$ & $18(6.7)$ \\
\hline \multicolumn{7}{|l|}{ Own a tattoo shop } \\
\hline Yes & $292(23.78)$ & $0(0)$ & $16(36)$ & $0(0)$ & $3(11)$ & $57(21.3)$ \\
\hline No & $751(61.16)$ & $1(100)$ & $20(44)$ & $1(100)$ & $21(75)$ & $158(59.0)$ \\
\hline Missing & $185(15.07)$ & $0(0)$ & $9(20)$ & $0(0)$ & $4(14)$ & $53(19.8)$ \\
\hline
\end{tabular}

\section{Discussion}

\section{Principal Findings}

The acceptance of tattoos has shifted greatly since tattoos were often associated with deviant behaviors in previous decades [28]. The tattoo community is more than people who have tattoos. On the basis of the previous literature, it is not easy to be considered a part of the tattoo community [28]. Having a tattoo does not automatically include individuals into the tattoo community. Even tattoo artists have a hierarchy, although tattoo artists may be accepted based on a shared profession. There is a devotion in the tattoo community that extends beyond having 
a tattoo, such as emphasizing the talent and elevating the profession to admired pieces of art.

Although tattoos are becoming mainstream, it was unclear if tattoo artists would be a hard-to-reach population. There is a paucity of research related to tattoo artists in the United States, so it was difficult to compare the recruitment efforts of other studies, including using social media or Web-based resources. The response to the Web-based survey was a surprise considering most of the responses occurred in the first 6 weeks of distribution, mainly from Facebook.

As so many tattoo artists use Instagram, it was expected that Instagram would have been effective in recruitment efforts. Instagram is readily used by tattoo artists to showcase their artwork, tattoos, and establish a Web-based portfolio. Instagram is beneficial because it is free for users and eliminates the added expenses for website domains and hosting. This is also a benefit for tattoo artists because they can develop their brand based on their name or alias, which is independent of a tattoo establishment. This is especially helpful for tattooists that do not own a tattoo establishment. However, the limitations of Instagram may have hindered its use, ultimately making it an ineffective recruiting tool in this study.

Email and Twitter both had a poor response rate. Emails can be cluttered with promotions, so this may influence the lack of response from email recruitment, especially if the recipient feels it was unsolicited. Tattoo artists may also prioritize their emails for clients or appointment inquiries. On the basis of the business cards that were collected from the tattoo artists' booths at the tattoo convention, Twitter handles were not included as frequently as Instagram or Facebook. This could be an indicator that Twitter is not as popular among tattoo artists. In addition, no paid advertisements were used on Twitter or Instagram.

Social media sites enhanced participation because it was an electronic platform that was easily distributed to reach tattoo artists nationwide. Social media may represent increased access to survey respondents [29] and is less costly than traditional recruitment methods [30]. The study sample included respondents from all 50 states. Of the recruitment methods used, Facebook ads were the most effective option, both for cost and recruitment rates. The cost per click rates varied between US $\$ 0.09$ and US \$0.43 for all Facebook ads that were directly linked to the Web-based survey. For the 2 advertisements targeting page likes that began in September and October, the cost per click rates were US $\$ 0.11$ and US $\$ 0.10$, respectively.

Overall, Facebook ads are promising for recruiting tattoo artists for a Web-based survey. Out of 2332 respondents, 1571 were tattoo artists. It is assumed that the remaining 761 respondents were not tattoo artists. All advertisements and recruiting materials specifically stated tattoo artists in the messages. The response from non-tattoo artists may indicate the benefit of using Facebook ads to recruit persons with tattoos or those interested in tattoos. This study's findings extend findings of the previous research studies that demonstrated the timeliness, ease, and effectiveness of using Facebook ads for recruitment.

\section{Limitations}

Use of social media leads to various limitations in research. This study's limitations include accessing only those with social media accounts during the specified timeframe, September 2015 to February 2016. Even though there was a large sample size, the results cannot be generalized, especially considering only tattoo artists were recruited. Using targeted Facebook ads may produce different outcomes with various populations. Also, race was not captured in the demographics of the Web-based survey, so it cannot be determined if this study's recruitment efforts had results similar to that of other studies where whites were more likely than ethnic minorities to respond to Facebook ads [31], although Facebook use among races is similar [1].

Although Instagram can be resourceful for tattoo artists, it has limitations for research and recruitment. At the time of this study, Instagram did not allow active website links in the text portion of image posts. Instagram only permits hyperlinks in the bio section of an Instagram profile. A website address can be provided in the text, but a person would have to either copy and paste the website address to go to the website or go to the profile to click on the hyperlink. This creates extra steps and reduces the ease of participation for Web-based surveys or recruitment efforts.

\section{Public Health Implications}

More people are getting tattoos, which is driving it into the mainstream culture. The technique used to create a tattoo involves opportunities for harmful health effects, such as infectious diseases, skin infections, and allergic reactions. Although there are health risks associated with tattoos, it is important to recognize the potential for integrating tattoo artists in skin health promotion.

Tattoo artists inspect a person's skin before tattoo placement, which is an opportune time to identify skin or mole irregularities that should be seen by a physician. Using sunscreen is essential in tattoo maintenance to help preserve ink colors and details in a tattoo, so this could be discussed along with using sunscreen for skin cancer prevention. Tattoo artists can spend many hours with a client in 1 tattooing session, so it is possible to have a conversation for 5 to $15 \mathrm{~min}$ about skin health promotion.

Using community members, such as hairstylists or clergy, has shown to be effective with various health topics. This concept could be extended to tattoo artists to reach more people for skin cancer prevention. Future research could explore tattoo artists' perceptions of engaging with clients about skin health topics. Using social media shows promise to reach this population.

\section{Conclusions}

Public health is dynamic and challenging, especially with the constant changes that occur in social norms and way of living. Technology has revolutionized lifestyles, and, as a result, has become embedded into daily activities. As practitioners, it is critical to evolve and encompass these digital tools to reach more people to improve their quality of life.

Although it cannot be expected to reach everyone through social media, Facebook ads showed to be effective in recruiting participants (ie, tattooers) for a Web-based tattoo survey. 
Overall, Facebook ads seem to be an acceptable option to reach this target population. In addition, it appears to be effective in reaching younger populations (ie, aged 18-49 years).

As social media platforms offer new features, it is important to reassess the use of Facebook ads along with other sites, such as Instagram. Since this study, Instagram has added video options, which demonstrates how quickly technology changes, which may reveal different impacts in the future. Continued research is needed for tattoo artists and tattoo consumers because of limited literature and studies for this population.

\section{Acknowledgments}

The original research project Evaluation of Tattoo Artists' Perceptions of Tattoo Regulations in the United States was reviewed and approved by the Georgia Southern University Institutional Review Board under tracking number H16069.

\section{Conflicts of Interest}

None declared.

\section{References}

1. Smith A, Anderson M. Pew Research Center. 2018. Social Media Use in 2018 URL: http://assets.pewresearch.org/wp-content/ uploads/sites/14/2018/03/01105133/PI 2018.03.01 Social-Media FINAL.pdf [accessed 2018-04-05] [WebCite Cache ID 6yStMK1kE]

2. Facebook Newsroom. 2018. Company Info URL: https://newsroom.fb.com/company-info/ [accessed 2018-04-05] [WebCite Cache ID 74puCqQnf]

3. Instagram. Instagram Search: \#tattooist URL: https://www.instagram.com/explore/tags/tattooist/ [accessed 2018-12-21]

4. Instagram. Instagram Search: \#tattooer URL: https://www.instagram.com/explore/tags/tattooer/ [accessed 2018-12-21]

5. Instagram. Instagram Search: \#tattooartist URL: https://www.instagram.com/explore/tags/tattooartist/ [accessed 2018-12-21]

6. Instagram. Instagram Search: \#tattoo URL: https://www.instagram.com/explore/tags/tattoo/ [accessed 2018-12-21]

7. Instagram. Instagram Search: \#tattoos URL: https://www.instagram.com/explore/tags/tattoos/ [accessed 2018-12-21]

8. Shannon-Missal L. The Harris Poll. 2016. Tattoo Takeover: Three in Ten Americans Have Tattoos, and Most Don't Stop at Just One URL: https://theharrispoll.com/tattoos-can-take-any-number-of-forms-from-animals-to-quotes-to-cryptic-symbolsand-appear-in-all-sorts-of-spots-on-our-bodies-some-visible-in-everyday-life-others-not-so-much-but-one-thi/ [accessed 2018-04-05] [WebCite Cache ID 6yRe6bEwg]

9. Centers for Disease Control and Prevention (CDC). Methicillin-resistant Staphylococcus aureus skin infections among tattoo recipients--Ohio, Kentucky, and Vermont, 2004-2005. MMWR Morb Mortal Wkly Rep 2006 Jun 23;55(24):677-679 [FREE Full text] [doi: 10.1097/01.inf.0000240350.61108] [Medline: 16791134]

10. Centers for Disease Control and Prevention (CDC). Tattoo-associated nontuberculous mycobacterial skin infections--multiple states, 2011-2012. MMWR Morb Mortal Wkly Rep 2012 Aug 24;61(33):653-656 [FREE Full text] [doi: 10.1111/j.1468-3083.2011.04359.x] [Medline: 22914227]

11. Ricciardo B, Weedon D, Butler G. Mycobacterium abscessus infection complicating a professional tattoo. Australas J Dermatol 2010 Nov;51(4):287-289. [doi: 10.1111/j.1440-0960.2010.00659.x] [Medline: 21198529]

12. Kazlouskaya V, Junkins-Hopkins JM. Pseudoepitheliomatous hyperplasia in a red pigment tattoo: a separate entity or hypertrophic lichen planus-like reaction? J Clin Aesthet Dermatol 2015 Dec;8(12):48-52 [FREE Full text] [Medline: 26705448]

13. Kluger N. Cutaneous complications related to tattoos: 31 cases from Finland. Dermatology 2017;233(1):100-109 [FREE Full text] [doi: 10.1159/000468536] [Medline: 28441655]

14. Dieckmann R, Boone I, Brockmann SO, Hammerl JA, Kolb-Mäurer A, Goebeler M, et al. The risk of bacterial infection after tattooing. Dtsch Arztebl Int 2016 Oct 7;113(40):665-671 [FREE Full text] [doi: 10.3238/arztebl.2016.0665] [Medline: 27788747]

15. Sapp JL. Georgia Southern University. 2016. Evaluation of Tattoo Artists' Perceptions of Tattoo Regulations in the United States URL: http://digitalcommons.georgiasouthern.edu/etd/1410

16. Lynch A, Ickes B, Kindred C, Morgan C, Seevers J, Croft L, et al. North Star Marketing. The Difference Between a Good Brand and a Great Brand? Consistency URL: https://www.northstarmarketing.com/2015/05/07/ the-difference-between-a-good-brand-and-a-great-brand-consistency/ [accessed 2018-04-05] [WebCite Cache ID 6yRcqtxOm]

17. World Tattoo Events. URL: https://www.worldtattooevents.com/ [accessed 2018-04-05] [WebCite Cache ID 6yRjOKwUA]

18. Florida Department of Health. Inspection Reports and Data: Tattoos URL: http://www.floridahealth.gov/statistics-and-data/ eh-tracking-and-reporting/tattoos.html [accessed 2018-04-05] [WebCite Cache ID 6yRj6z9iy]

19. Dusek GA, Yurova YV, P. Ruppel CP. Using social media and targeted snowball sampling to survey a hard-to-reach population: a case study. Int J Doctoral Stud 2015;10:279-299 [FREE Full text] [doi: 10.28945/2296]

20. Baltar F, Brunet I. Social research 2.0: virtual snowball sampling method using Facebook. Internet Res 2012 Jan 27;22(1):57-74. [doi: 10.1108/10662241211199960] 
21. Statista. Daily Time Spent on Social Networking by Internet Users Worldwide From 2012 to 2017 (in Minutes) URL: https://www.statista.com/statistics/433871/daily-social-media-usage-worldwide/ [accessed 2018-04-07] [WebCite Cache ID 6yRjtrLTw]

22. Qualtrics. Embedded Data URL: https://www.qualtrics.com/support/survey-platform/survey-module/survey-flow/ standardelements/embedded-data/ [accessed 2018-04-05] [WebCite Cache ID 6yRdMle9s]

23. Reiter PL, Katz ML, Bauermeister JA, Shoben AB, Paskett ED, McRee AL. Recruiting young gay and bisexual men for a human papillomavirus vaccination intervention through social media: the effects of advertisement content. JMIR Public Health Surveill 2017 Jun 2;3(2):e33 [FREE Full text] [doi: 10.2196/publichealth.7545] [Medline: 28576758]

24. Carter-Harris L, Bartlett ER, Warrick A, Rawl S. Beyond traditional newspaper advertisement: leveraging Facebook-targeted advertisement to recruit long-term smokers for research. J Med Internet Res 2016 Dec 15;18(6):e117 [FREE Full text] [doi: 10.2196/jmir.5502] [Medline: 27306780]

25. Hudnut-Beumler J, Po'e E, Barkin S. The use of social media for health promotion in Hispanic populations: a scoping systematic review. JMIR Public Health Surveill 2016 Jul 11;2(2):e32 [FREE Full text] [doi: 10.2196/publichealth.5579] [Medline: 27400979]

26. Adam LM, Manca DP, Bell RC. Can Facebook be used for research? Experiences using Facebook to recruit pregnant women for a randomized controlled trial. J Med Internet Res 2016 Sep 21;18(9):e250 [FREE Full text] [doi: 10.2196/jmir.6404] [Medline: 27655184]

27. Laws RA, Litterbach EK, Denney-Wilson EA, Russell CG, Taki S, Ong KL, et al. A comparison of recruitment methods for an mhealth intervention targeting mothers: lessons from the growing healthy program. J Med Internet Res 2016 Dec 15;18(9):e248 [FREE Full text] [doi: 10.2196/jmir.5691] [Medline: 27634633]

28. DeMello M. Bodies of Inscription: A Cultural History of the Modern Tattoo Community. Durham, North Carolina: Duke University Press; 2000.

29. Murphy J, Link MW, Childs JH, Tesfaye CL, Dean E, Stern M, et al. American Association for Public Opinion Research. 2014. Social Media in Public Opinion Research: Report of the AAPOR Task Force on Emerging Technologies in Public Opinion Research URL: http://www.aapor.org/AAPOR_Main/media/MainSiteFiles/AAPOR_Social_Media_Report_FNL. pdf [accessed 2018-04-05] [WebCite Cache ID 6ySygtKAR]

30. Whitaker C, Stevelink S, Fear N. The use of Facebook in recruiting participants for health research purposes: a systematic review. J Med Internet Res 2017 Dec 28;19(8):e290 [FREE Full text] [doi: 10.2196/jmir.7071] [Medline: 28851679]

31. Guillory J, Wiant KF, Farrelly M, Fiacco L, Alam I, Hoffman L, et al. Recruiting hard-to-reach populations for survey research: using Facebook and Instagram advertisements and in-person intercept in LGBT bars and nightclubs to recruit LGBT young adults. J Med Internet Res 2018 Dec 18;20(6):e197 [FREE Full text] [doi: 10.2196/jmir.9461] [Medline: 29914861]

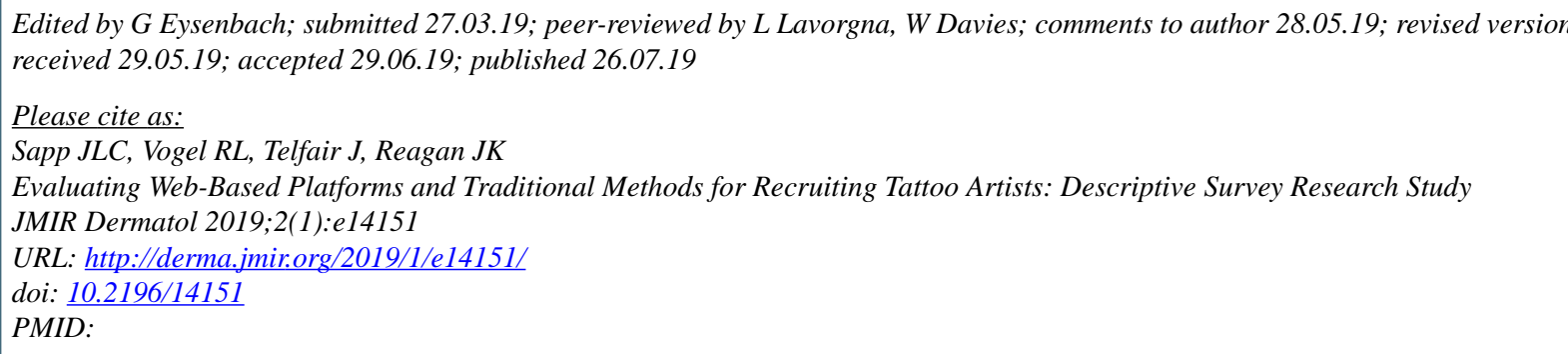

(CJessica LC Sapp, Robert L Vogel, Joseph Telfair, Julie K Reagan. Originally published in JMIR Dermatology (http://derma.jmir.org), 26.07.2019. This is an open-access article distributed under the terms of the Creative Commons Attribution License (https://creativecommons.org/licenses/by/4.0/), which permits unrestricted use, distribution, and reproduction in any medium, provided the original work, first published in JMIR Dermatology Research, is properly cited. The complete bibliographic information, a link to the original publication on http://derma.jmir.org, as well as this copyright and license information must be included. 